\title{
Learning How to Program in C Using Adaptive Hypermedia System
}

\author{
Patricia Anthony, Natasha E. Joseph, and Christina Ligadu
}

\begin{abstract}
This paper describes an adaptive hypermedia system, MyC that is used by students as a tool to assist them in learning $\mathrm{C}$ programming. $\mathrm{MyC}$ generates lessons and learning paths that correspond to specific learning goals to accommodate both learners' level of knowledge and learning style. This system was tested with a group of first year engineering students who took an introductory $C$ programming course. The evaluations showed that students who used the system showed an improvement on their overall academic assessments. This strongly indicates that $\mathrm{MyC}$ can be used as a tool to assist students in $\mathrm{C}$ programming.
\end{abstract}

Index Terms-Adaptive hypermedia system, learning style, honey and mumford.

\section{INTRODUCTION}

Over the years, several studies have shown that there has been attrition in computer science programs [1]. These studies suggest that the major contributing factors include lack of experience in computing before entering colleges or universities, limited or poor preparation in math, poor self-efficacy, socialization and the university environment. Investigations have additionally found that students with no prior programming experience are at a disadvantage in successfully completing a computer science degree [2]-[4].

To assist students, most institutions provide Learning Management System (LMS) that enables students to download course materials and engage in interactive sessions such as live discussions and forums. Most LMSs provide similar e-learning tools for course designers such as wiki, glossary tools and student profile features. The course content delivered by LMSs to the students are based on the assumption that all leaners learn the same way using the same materials and they progress towards the lesson in tandem with their peers. LMSs overlook on the personalization of its learner as it is based on a "one size fits all" mentality. The fundamental problem is that learners have diverse backgrounds, abilities and motivations and thus, require different learning requirements. Many learners who use this kind of system become increasingly dissatisfied since the content is static, it is not interactive and it is not sensitive to

Manuscript received October 25, 2012; revised January 02, 2013.

P. Anthony is with the Department of Applied Computing, Faculty of Environment, Society and Design, Lincoln University, P. O. Box 84, Lincoln University, Lincoln 7647, Christchurch, New Zealand (e-mail: patricia.anthony@lincoln.ac.nz).

N. E. Joseph is with the School of Engineering and Information Technology, Universiti Malaysia Sabah, Jalan UMS, 88999 Kota Kinabalu, Sabah , Malaysia (e-mail: nshajoseph @ gmail.com).

C. Ligadu is with the School of Education and Social Development, Universiti Malaysia Sabah, Jalan UMS, 88999 Kota Kinabalau, Sabah, Malaysia (e-mail: ligadu@ums.edu.my). the needs of the users [5]. A possible remedy is the Adaptive Hypermedia System (AHS) which contradicts the LMS approach of "one size fits all".

In traditional classrooms, there have been clear improvements in students' achievements levels where students are taught based on their diagnosed learning style [6]. Learning style is best described as the complex manner in which learners most efficiently and most effectively perceive, process, store and recall what they are attempting to learn. Learning style models have been researched and used by educationalist for many years. There are many different learning style models such as [7]-[9]. Due to the various learning style models' success in distinguishing how a person learns, educationalists have tried to incorporate these models into adaptive hypermedia systems. Kolb and Felder-Silverman learning styles have been used effectively in engineering education, while Honey and Mumford learning style model was used in business and management education [10]. To further enhance its effectiveness, aspects such as user modeling is also taken into account. For example, the students' individual profiles such as gender, age, their knowledge level and their individual progress are incorporated into the adaptive hypermedia system.

This system was used by first year engineering students who were taking introductory programming in $\mathrm{C}$ language in one of the higher level institutions in Malaysia. In that particular institution, the average number of students in a programming class is between 80 and 100. It was also observed that having a large class has made it difficult for the lecturer to provide adequate attention to each individual student. As suggested by [6], teaching programming concepts to a large number of students is not advisable. The class should be kept small (between 30 and 50 students) to ensure effective learning to take place. However, this institution was not able to implement this as there were shortages of lecturers and teaching resources.

In order to address this problem, we developed a web based adaptive hypermedia system $(\mathrm{MyC})$ that was used by the students as a learning resource to better understand $\mathrm{C}$ language. $\mathrm{MyC}$ generates lessons that correspond to specific learning goals to accommodate both learners' knowledge level and learning style. It emphasizes on individualization and is tailored to each different learning style of each student. We incorporated Honey and Mumford learning style model in $\mathrm{MyC}$. The aim of this study is to firstly determine whether the use of adaptive hypermedia that incorporates learning style and students' knowledge level is able to assist the students to learn programming. Secondly, we would like to investigate whether using Honey and Mumford learning style (which is more suitable for business and management education) can be used in an engineering and technology 
education.

The remainder of this paper is structured as follows. In Section II, we will describe some of the related work in hypermedia systems that combined various learning style to improve student learning. We describe some of the existing learning styles in Section III. The design on $\mathrm{MyC}$ will be described in Section IV. The learning modules for the four types of learner are described in Section V. The experimental setup and the results of the experimental evaluation are discussed in Section VI. Finally, the conclusion and future work is discussed in Section VII.

\section{RELATED WORK}

There have been a lot of interests in the development of adaptive hypermedia systems that incorporate various learning styles to improve and enhance students' learning experiences. Liegle and Janicki conducted an exploratory experiment for a group of 68 undergraduate students who were enrolled in the Principle of Management course [11]. They used Kolb Learning Style to measure their learner's learning style preferences. The learners' navigational behavior was constantly monitored and logged. The learners navigate through each of the learning content by clicking the "Next" button. Alternatively, the learners can also click on the "Jump" button to go to a different link via a hyperlinked "Table of Contents" that was presented on the web page. When the learning process was completed, the learners were required to complete an online quiz. Their study found that learners classified as "Explorers" tended to control their own learning path, while learners classified as "Observer" tended to follow the suggested path. The test scores for the "Explorers" who jumped to another page were higher than the "Explorers" who did not jump at all. Similar observations were recorded for the "Observers" group.

Mustafa and Sharif developed and adaptive hypermedia system (AHES-LS) to enable them to assess the effect of adapting educational materials that are individualized to the student's learning style [12]. AHES-LS consist of three basic models which are the domain model, the student model and the adaptation model. The domain model structures the knowledge about the domain to be learned while the student model provides a complete description of the state of the learner. The implementation of the adaptation rules is handled by the adaptation model. AHES-LS used the Fleming's VARK learning style model in which the students are classified into four categories of visual preference, auditory perceptual mode, read/write preference and kinesthetic modality. The learning materials and media presentation for each student is based on the learner's profile. Students need to answer an evaluation quiz for each lesson and the result of this evaluation will be used by AHES-LS to adapt the knowledge and learning preference. Their findings showed that students taught using AHES-LS performed significantly better in academic achievement than students taught the same material without adaptation to learning style.

Mampadi et al. developed an adaptive hypermedia learning system tailored to students' cognitive styles with an emphasis to Pask's Holist-Serialist dimension [13]. In this study, they examined the students' reaction to the system in terms of learning performance and perception. Students are asked to answer a set of questionnaire and based on the result of the survey they are then categorized into Serialists or Holists. Half of the group in both Serialists and Holists were asked to use the adaptive hypermedia system (AHLS) and the other half were asked to use the ordinary hypermedia system without the adaptation (OHLS). Students were required to take the pre-test and post-test so that their levels of knowledge of the subject domain can be assessed. The results of the experiment showed that the students using AHLS showed better performance and bigger improvement than those using OHLS regardless of their cognitive styles. Both Serialists and Holists using AHLS also demonstrated more positive perceptions towards structure clarity and logical sequence than those using OHLS.

Another system called Protus, was able to automatically adapt to the interests and knowledge levels of the learners [14]. It recognizes different patterns of learning style and learner's habit by testing the learning styles of learners and mining their server logs. This system was used as a general tutoring for different programming languages and in this particular experiment it was for an introductory Java programming course. The results of the experiment showed that learners in the experimental group were able to complete a course in less time than learners in the control group. Learners also found that the system was able to guide them to appropriate materials and provide useful additional explanations.

Finally, Lee proposed an adaptive courseware that provides instruction content based on the most effective instruction method for the learner by taking into consideration his or her learning style [15]. In this study, Kolb's learning style was used to identify learners. This courseware was used to aid students for a computer encryption subject at a college level. However, no experimental evaluation was documented.

\section{Honey ANd Mumford LEARning STYle MOdEL}

One of the methods that will be used in this study is the learning style adaptation. The field of cognitive science defines the theory of learning style as "an individual's and habitual approach to organizing and representing information" [16]. In the literature, there exist numerous learning styles and learning style models. Kolb defines learning style as the different ways used by individuals to process and organize information to respond to environmental stimuli [8]. To Kolb, learning style is a method of personal choice to perceive and process information. In this sense, learning style is on one hand sensory, and on the other hand, mental. Among the most popular learning style models used in adaptive hypermedia systems are Kolb Learning Style Model [8], Honey and Mumford Learning Style Model [9] and Felder-Silverman Learning Style Model [7].

Kolb Learning Style Model [8] classifies every learner as having preference for concrete experience or abstract conceptualization (how to perceive information) and active experimentation or reflexive observation (how to process information). Kolbs defined four types of learners; a diverger with concrete experience and reflective observation, an assimilator with abstract conceptualization and active experimentation and an accommodator with concrete 
experience and active experimentation.

On the other hand, Felder-Silverman Learning Style Model [7] emphasizes on finding a balance between teaching strategies and learners learning styles in order to accomplish effective learning. The model classifies an individual's preferred learning style by a sliding scale of four dimensions; sending-intuitive, visual-verbal, active-reflective and sequential-global.

Honey and Mumford [9] adapted the experiential model which identifies four types of learners called Theorist, Reflector, Activist and Pragmatist. This learning model is assumed to be acquired preferences that are adaptable, whether at will or through changed circumstances rather than being fixed personality characteristic. Theorists like to understand the theoretical aspect behind all actions. They need concepts, models and facts as their learning process. They prefer to analyze and synthesize every bit of new information in a systematic and logical manner. Reflectors learn by observing and by reflecting each learning outcome or goal. They are not spontaneous but prefer to stand back and view experiences from a number of perspectives, collecting data and taking time to find an appropriate conclusion. Activists are learners who learn by doing and discover things for themselves. They need to get practical and get their hands dirty in learning a certain concept. Finally, pragmatists need to be able to see how to put the learning into practice in the real world. They like to see the relevance and real world applicability to whatever they are learning.

\section{MYC ARCHITECTURE}

The framework for MyC was derived from Adaptive Hypermedia Architecture Model (AHAM) and the generalized architecture of adaptive educational hypermedia systems [17]. The overall physical design of MyC consists of the user interface in the form of a web browser, a web server and a database to store information relating to learning modules, the user profile and the adaptive profile. Fig. 1 shows the system architecture of MyC.

Each student is asked to fill in a questionnaire that consists of two parts. The first part of the questionnaire consists of 10 questions to gauge the students' level of knowledge in mathematics and programming. Based on this questionnaire, students will be divided into Advanced, Average and Poor. The second part of the questionnaire consists of 80 -item Learning Style Questionnaire (LSQ) based on Honey and Mumford [18] which is used to categorize the students into four learners type (Theorist, Reflector, Activist and Pragmatist). By combining the students' level of knowledge and the learning style, students can then be categorized as Theorist-Average, Theorist-Advanced, Theorist-Poor, such that there are 12 categories of students. We also developed four learning modules that will be used by the four groups of students (the detail of this is elaborated in the Section V). Based on their categorization, each student will be presented with their learning modules and the proposed learning path that they should follow. Students are then assessed through individual quiz, midterm and final exam. Based on their assessments' result, it is possible for the students to be re-categorized where new learning modules and learning path will be re-generated for them. The learner profile, progress, test scores and additional information is kept and maintained in a database.

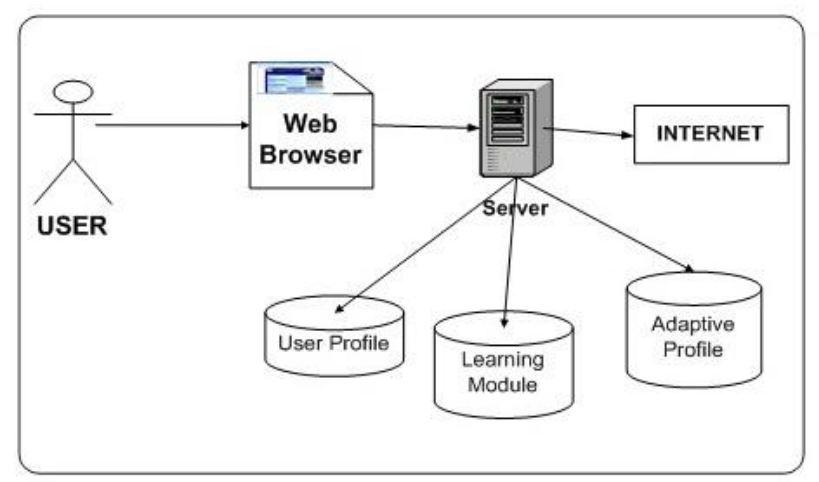

Fig. 1. MyC system architecture.

\section{CATEgorization Of LEARners Based ON HONEy AND MUMFORD LEARNING STYLE MODEL}

The learning modules of the learners are developed based on Honey and Mumford Learning Style Model. In our system, Theorist learners are provided with a lot of texts that focus on the theoretical aspects related to learning $\mathrm{C}$ programming. As such, the learning modules contain a lot of concepts and facts to allow the students to analyze and disseminate the information in a logical manner. The information is presented in plain text and is organized in a structured manner.

The main criterion for Reflectors is that they need to know the objectives of what they are learning and what they are able to achieve at the end of the module. We designed the learning modules to accommodate this by adding a "What will you learn" and "Objectives" sections. Reflectors are also given a set of questions at the end of every module to test whether they have understood the module and whether they have achieved the predefined objectives.

Activists learn best by being more active and they learn through action and discovery. For this group of learners, we incorporated animations and graphics into the learning module. We are also aware that activist learners are not bothered by the theoretical information that is presented in the module. That is why we provided them with options to hide certain information as they like.

Finally, pragmatist learners are more practical in nature as they need to be able to see how to apply what they have learned in real world. For this group of learners, we provide real world exercises and problems at the end of each module so that they can figure out the solutions to these exercises and experience how to solve real world problems.

\section{EXPERIMENTAL EVALUATION}

We conducted the experiment for a period of five months during a normal semester for a group of first year engineering students who were registered for the introductory course in C programming. The students were divided into two groups which are the experimental group and the control group. The experimental group is the group of students who used the system based on their learning style and level of knowledge. On the other hand, the control group is the group of students 
who used the system with a fixed learning module. Here, the control group was given the Theorist learning module and they used the module throughout the semester. We made no attempt to match the learning module with their learning styles and knowledge levels. The purpose of doing this is to assess whether adaptation based on Honey and Mumford learning style will produce better result in terms of academic achievement.

Table I shows the distribution of students across the two groups. Students were assessed in three stages which consist of one quiz conducted at the beginning of the semester, one midterm conducted in the middle of the semester and the final exam which is conducted at the end of the semester. The final exam is the most important assessment as it measures the overall performance of the students whilst the quiz and the midterm only measures the performance of the students based on certain modules.

TABLE I: DIVISION OF LEARNERS

\begin{tabular}{cccc}
\hline \hline Types & Experimental & Control & Total \\
\hline Theorists & 6 & 6 & 12 \\
Reflectors & 11 & 11 & 22 \\
Activists & 5 & 5 & 10 \\
Pragmatists & 4 & 4 & 8 \\
Total & 26 & 26 & 52 \\
\hline \hline
\end{tabular}

Fig. 2 shows the results obtained by the experimental and control group based on the three assessments. It can be seen that the experimental group did better in all the assessments. They scored an average of 36.90 for the quiz, 49.50 for the midterm and 60.81 for the final exam. These average scores are higher than the average scores obtained by the control group. The experimental group surpassed the average scores of the control group by an average difference of $6.74 \%$. This indicates that students who used the system with adaptation did better than the students who used a fixed learning module.

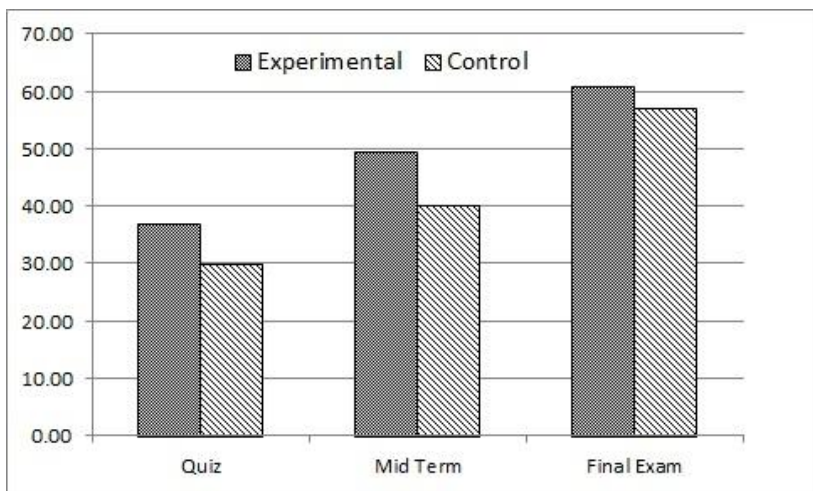

Fig. 2. Overall performance of the experimental group vs. the control group.

The performance of the Theorist learners is shown in Fig. 3. As can be seen, the experimental group performed better that the control group in all the assessments by scoring 37.78 , 58.89 and 71.33 in the quiz, midterm and final exam. The group also improved over the semester by consistently scoring an increasing average in all the tests. This upward trend is also prominent in the control group. However, the end result showed that the experimental group did better than the control group as their average scores are higher than the control group's average scores.

The results for the Reflector learners, Activist learners and
Pragmatist learners can be observed in Fig. 4, Fig. 5, and Fig. 6 . The results obtained are consistent throughout the different learners' group. It can be seen that experimental learners who are using adaptation did better than the control group. Fig. 6 shows a slight variation in students' performance in that the control group did better in the first quiz. However, the experimental group was able to overtake these learners in their midterm and final exam. This clearly shows that as the learners progress through the learning modules, their learning rate also improved.

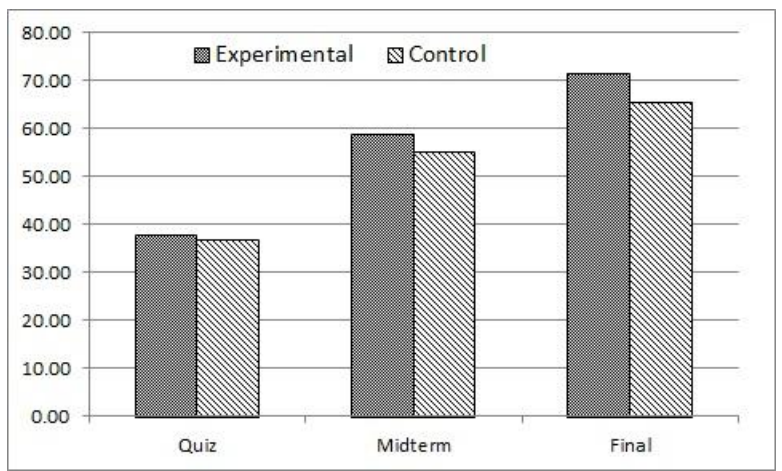

Fig. 3. Performance of the theorist experimental group vs. theorist control group.

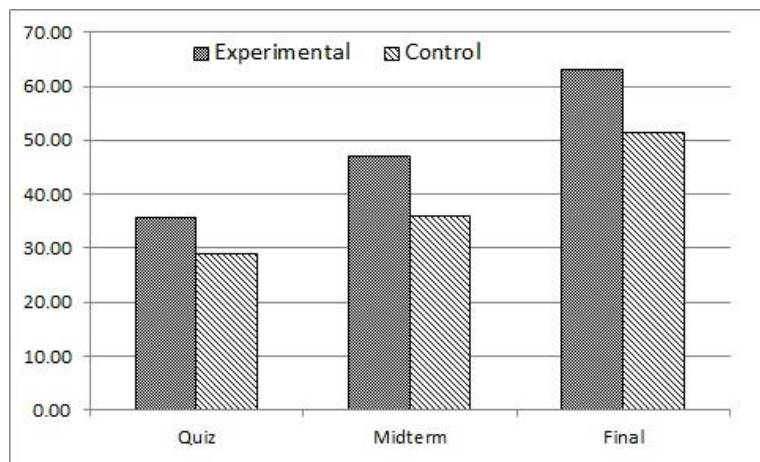

Fig. 4. Performance of the reflector experimental group vs. reflector control group.

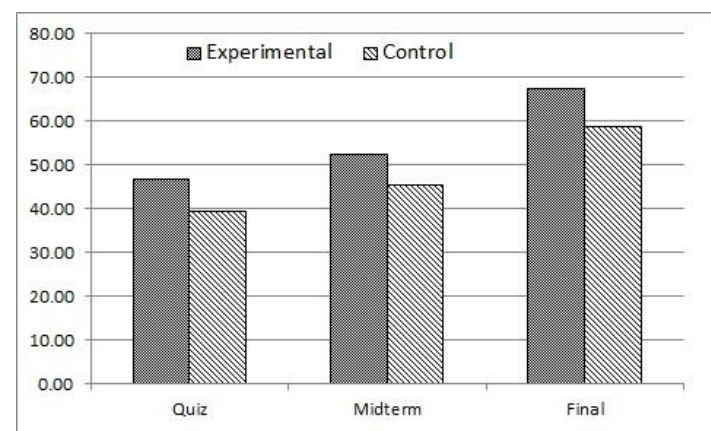

Fig. 5. Performance of the activist experimental group vs. reflector control group.

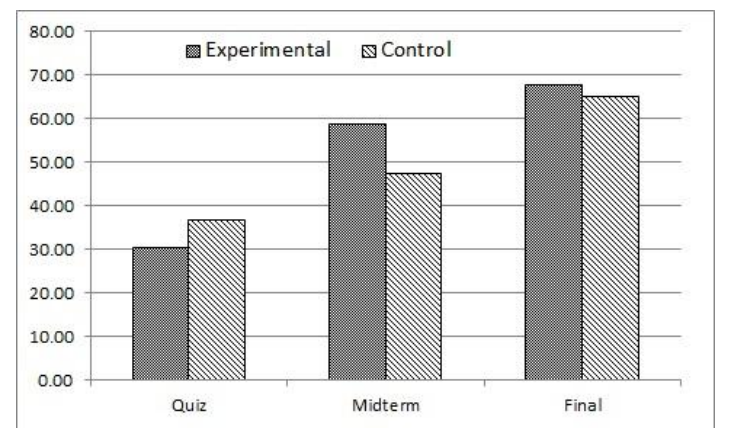

Fig. 6. Performance of the pragmatist experimental group vs. reflector. 


\section{CONCLUSION AND FUTURE WORKS}

This paper describes MyC, an adaptive hypermedia system that is based on Honey and Mumford Learning Model. The learning module in MyC is personalized and is generated based on the student's learning style and knowledge level.

Our finding showed that MyC learners did well in all the assessments compared to those learners who were using a fixed learning module without personalization and adaptation. We used Honey and Mumford Learning Model to classify the learning style of the learners even though we were aware that this model is recommended to be used in business and management education setting. However, the performance of the learners showed that this model can also be used in engineering and technology education setting. The findings in this study suggest that identifying the different learning styles can be utilized to assist students to succeed in their study and accelerate the learning process. As pointed out by Kolb [8], people learn differently based on their learning style and how they learn will indirectly affect their transfer of knowledge.

There are several areas in which we can extend this study. Firstly, we would like to explore the possibility of using artificial intelligence techniques to identify student learning style based on their interactions with the system rather than getting them to answer a set of questionnaire. We would also like to explore the idea of integrating different learning styles to help learners learn more effectively in a wider range of educational experiences. Further research would be needed, however, to show which types of experiential exercises are effective in promoting particular types of learning mode, how difficult it would be to change one's normal learning preferences, and whether understanding and reflecting on one's learning style will necessarily lead to better learning abilities.

\section{REFERENCES}

[1] B. Moskal, D. Lurie, and S. Cooper, "Evaluating the effectiveness of a new instructional approach," SIGCSE Bulletin, vol. 36, no. 1, pp. 75-79, 2004.

[2] P. Byrne and G. Lyons, "Factors affecting performance in first year computing," SIGCSE Bulletin, vol. 32, no. 2, pp. 39-43, 2001.

[3] D. Hagan and S. Markham, "Does it help to have some programming experience before beginning a computing degree program?" SIGCSE Bulletin, vol. 32, no. 3, pp. 25-28, 2000.

[4] T. Beaubouef and J. Mason, "Why the high rate for computer science students: some thoughts and observations," SIGCSE Bulletin, vol. 37, no. 2, pp. 103-106, 2005.

[5] P. Brusilovsky, "KnowledgeTree: A distributed architecture for adaptive e-learning," in Proc. 13th International World Wide Conference in Alternate Track Paper \& Posters (WWW Alr. '04), New York, 2004, pp. 104-113.

[6] A. Goold and R. Rimmer, "The effect of student attributes on success in programming," SIGCSE Bulletin, vol. 33, no. 3, pp. 49-52, 2000.

[7] R. M. Felder and L. K. Silverman, "Learning and teaching styles in engineering education," Engineering Education, vol. 78, no. 7, pp. 674-681, 1988

[8] D. A. Kolb, Experiential learning: Experience as the source of learning and development, New Jersey, USA: Prentice Hall, 1984.
[9] P. Honey and A. Mumford, The Manual of Learning Styles, Coventry, U.K.: Peter Honey Publications, 1992.

[10] A. V. Zwanenberg, L. J. Wilkinson, and A. Anderson, "Felder and Silverman's index of learning styles and Honey and Mumford learning styles questionnaire: How do they compare and do they predict academic performance?" Educational Psychology: An International Journal of Experimental Educational Psychology, vol. 20, no. 3, pp. 365-380, 2000.

[11] J. O. Liegle and T. N. Janicki, "The effect of learning styles on the navigation needs of web based learners," Computers in Human Behavior, vol. 22, pp. 855-898, 2006.

[12] Y. E. Mustafa and S. M. Sharif, "An approach to Adaptive E-Learning Hypermedia System based on Learning Styles (AEHS-LS) Implementation and evaluation," Journal of Library ad Information Science, vol. 3, no. 1, pp. 15-28, 2011.

[13] F. Mampadi, S. Y. Chen, G. Ghinea, and M. Chen, "Design of adaptive hypermedia learning systems: A cognitive style approach," Computers \& Education, vol. 56, pp. 1003-1011, 2011.

[14] A. K. Milicevic, B. Vesin, M. Ivanovic, and Z. Budimac, "E-Learning personalization based on hybrid recommendation strategy and learning style identification," Computers \& Education, vol. 56, pp. 885-899, 2011.

[15] J. Lee, "Adaptive courseware using Kolb's learning styles," International Magazine on Advances in Computer Science and Telecommunications, vol. 3, no. 1, pp. 45-49, 2012.

[16] C. McLoughlin, "The implications of the research literature on learning styles for the design of instructional material," Australian Journal of Education Technology, vol. 15, no. 3, pp. 222-241, 1992

[17] P. Karampiperis and D. Sampson, "Adaptive learning resources sequencing in educational hypermedia systems," Educational Technology \& Society, vol. 8, no. 4, pp. 128-147, 2012.

[18] P. Honey and A. Mumford, The Learning Styles Questionnaire, 80-item version, Maidenhead, U.K.: Peter Honey Publications, 2006.

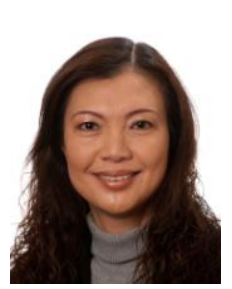

Patricia Anthony received her $\mathrm{PhD}$ in Computer Science from the University of Southampton in 2003 She is currently working as a Senior Lecturer at the Department of Applied Computing, Lincoln University, New Zealand. Her research interest is in semantic agents and multi-agent systems and how these agents can interact with each other within an open domain to solve problems. She is also interested in investigating how agents can communicate with each other at the semantic level using semantic technology. To date, she has published more than 80 articles in the forms of journals, book chapters and conference proceedings. She is a member of IEEE and ACM.

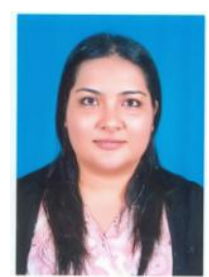

Natasha E. Joseph is a postgraduate student at the Universiti Malaysia Sabah. She obtained her BSc(Hons) in Computer Science from Universiti Malaysia Sarawak and is currently working at Micronet International College in Brunei Darussalam. She is interested in finding ways for students to better retain their knowledge and to inculcate the love of programming among new learners using ICT.

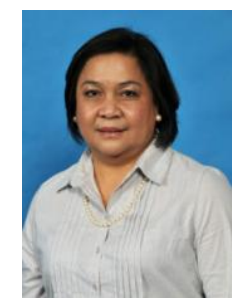

Christina Ligadu received her $\mathrm{PhD}$ in Mentoring and Supervision in Education from the University of Wollongong, NSW, Australia. She is currently working as an Associate Professor at the School of Education and Social Development, Universiti Malaysia Sabah. Her research interests are mentoring, supervision, pedagogy in schools and higher education and qualitative studies. She has published various articles on effective mentoring. She is also a member of the Malaysian Qualitative Research 